\title{
A method for determining when the superficial scalp arteries are the source of migraine pain
}

\author{
E Shevel, BDS, Dip MFOS, MB BCh \\ The Headache Clinic, Johannesburg, South Africa
}

Corresponding author: E Shevel (drshevel@headclin.com)

In some patients the pain of migraine originates in the extracranial cranial arteries. This article describes the location and a logical examination sequence of the vessels most frequently involved in migraine pain.

S Afr Med J 2017;107(8):691-693. DOI:10.7196/SAMJ.2017.v107i8.12417

Migraine is a common disorder with a worldwide lifetime prevalence of $16 \%$, and a last-year prevalence of $10 \% .^{[1]}$ There is a great deal of evidence showing that painful dilation of the terminal branches of the external carotid arteries is the source of the pain in many but not all migraine sufferers. ${ }^{[2]}$ In a study of 63 migraineurs, digital compression of the ipsilateral superficial temporal artery during migraine headache temporarily reduced or eliminated the pain in $23(36 \%)$ cases. ${ }^{[3]}$ Migraine pain can also originate in the pericranial muscles. ${ }^{[4,5]}$ Although migraine is one of the most common reasons for patients visiting their general practitioner, the study curriculum in medical schools does not include instruction on how to examine migraine sufferers to determine whether their pain originates in the terminal branches of the external carotid artery, the pericranial muscles, or both. The importance of accurate diagnosis of the source of the pain cannot be overemphasised. The abortive treatment of choice for migraine is one of the ergot alkaloids or triptans, which are vasoconstrictors that act upon the terminal branches of the external carotid artery. ${ }^{[6-9]}$ In this article a protocol is described for the clinical evaluation of the terminal branches of the external carotid artery to diagnose which patients have vascular pain and in whom vasoconstrictors are the most likely to be effective.

\section{Anatomy}

The scalp derives its blood supply mainly from the four superficial branches of the external carotid artery, the superficial temporal, angular, occipital, and posterior auricular arteries, and the supraorbital and supratrochlear branches of the internal carotid. There are extensive anastomoses between these arteries, homolateral and heterolateral, the latter crossing the midline, and therefore able to vascularise the opposite side of the scalp. ${ }^{[10]}$ There is an anastomosis crossing between the left and right sides every $5-7 \mathrm{~mm}$. Intertemporal anastomoses are by far the most numerous, followed by inter-occipital. As a result of this vast network of anastomoses, the blood supply of the scalp takes the form of a rich network of interconnecting vessels. These connections vary among patients and from left to right in the same patient. ${ }^{[10]}$

\section{Superficial temporal artery - main trunk}

The superficial temporal artery bifurcates anterior to the auricle to become two major branches, the frontal and the parietal. ${ }^{[1]}$ The frontal branch runs toward the midline of the forehead above the eyebrow, and the parietal branch supplies the parietal region (Fig. 1) ${ }^{[12]}$ The main trunk is most accessible where it crosses superficial to the zygomatic process of the temporal bone just anterior to the tragus. ${ }^{[13]}$ The superficial temporal artery is sometimes very small, in which case it may be replaced by the posterior auricular artery. It at times also communicates with the supraorbital artery to supply the forehead. ${ }^{[14]}$

\section{Superficial temporal artery - frontal branch}

The frontal branch of the superficial temporal artery runs a tortuous course just subcutaneously, crossing the temple in an anterosuperior direction (Fig. 1). It is often visible, particularly during a migraine attack. Although it is a terminal branch of the superficial temporal artery, because of its extensive anastomoses in the scalp, the frontal branch is not supplied exclusively by the superficial temporal artery, but also by other scalp vessels. ${ }^{[12]}$

\section{Posterior auricular artery}

The posterior auricular artery emerges from the deeper tissues in the groove between the cartilage of the ear and the mastoid process (Fig. 1), and immediately divides into its auricular and occipital branches. When the posterior auricular is larger than usual it may be compensating for a deficiency in either the occipital or superficial temporal arteries. ${ }^{[14]}$

\section{Occipital artery}

The occipital artery emerges from the deep tissues of the neck, and pierces the fascia between the attachments of the sternomastoid and

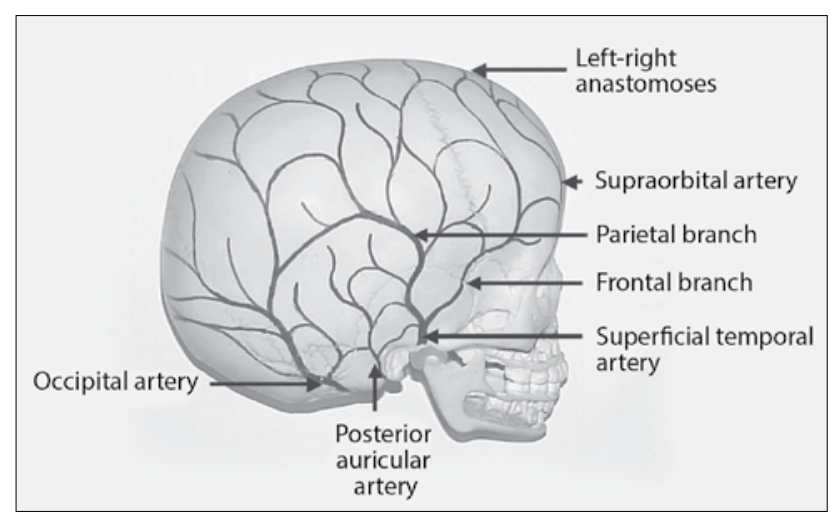

Fig. 1. The extensive arterial anastomotic network of the terminal branches of the external carotid artery. 
trapezius muscles at the level of the superior nuchal line. It then ascends in a tortuous course in the superficial fascia of the scalp, where it divides into numerous branches, which reach as high as the vertex of the skull, and anastomoses with the posterior auricular and superficial temporal arteries. ${ }^{[15]}$ It also anastomoses with the contralateral occipital artery. ${ }^{[10]}$

\section{Supraorbital and supratrochlear arteries}

The supraorbital and supratrochlear arteries emerge superficially at or near the supraorbital foramen to supply the forehead, and anastomose with the frontal branch of the superficial temporal and the supraorbital and supratrochlear arteries of the opposite side (Fig. 1). ${ }^{[15]}$

\section{Angular artery}

The angular artery is the terminal branch of the facial artery. It runs up the lateral surface of the nose, and terminates in the frontal tissues (Fig. 1). ${ }^{[15]}$

\section{Methods}

In some patients with migraine headache, reduction of the blood pressure in the painful area by digital occlusion of one or more of the superficial arteries reduces or eliminates the pain while the pressure is being applied. ${ }^{[3,16-21]}$

Before the examination commences, the patient is asked to estimate the severity of the headache according to a scale of $0=$ no pain to $10=$ the worst pain possible, and the severity is recorded.

As each artery is compressed, the patient is asked to estimate the percentage of pain relief, if any, and which is recorded. It is interesting that in patients who report pain relief with digital arterial compression, in some the pain returns the moment the pressure is relieved, and in others the pain takes time to return.

The arteries are examined in the following sequence:

- superficial temporal - main trunk

- superficial temporal - frontal branch

- occipital

- posterior auricular

- angular

- supraorbital and supratrochlear.

One or more of the abovementioned arteries may be involved in the pain process.

It is necessary to bear in mind that because of the variability of the anastomoses between these vessels, it may be difficult to diagnose accurately which arteries are contributing blood flow to the painful area. Arteries distant from the painful area may also be involved in the pain mechanism. A common finding, for example, is that compression of the occipital artery may alleviate ipsilateral periorbital pain.

When the pain is unilateral, the ipsilateral artery is compressed first, then the contralateral artery, then both left and right simultaneously. If the pain is bilateral, the left and right sides are compressed simultaneously.

\section{Superficial temporal artery - main trunk}

The superficial temporal artery passes superficial to the posterior root of the zygomatic arch just anterior to the tragus. Gentle palpation of this area often reveals the presence of a pulse, which is frequently more prominent during a migraine attack. Applying digital pressure over the zygomatic arch, thereby compressing the artery against the arch, temporarily occludes the artery. As the anteroposterior distance of the artery from the tragus is variable, the following method is used to ensure its compression: The examiner stands in front of the patient and compresses the tissues anterior to the tragus against the zygomatic arch with the fingertip touching the tragus and the finger parallel to the arch. This ensures that all the tissues up to at least $2.5 \mathrm{~cm}$ anterior to the tragus are compressed (Fig. 2).

If the pain improves or disappears when the contralateral artery is compressed, it indicates a substantial anastomotic connection between left and right.

\section{Superficial temporal artery - frontal branch}

The examiner stands in front of the patient, with the patient's head inclined backwards at $\sim 45^{\circ}$ to the horizontal. The flat part of the finger is applied to the temple to compress the tissues along a line extending from the outer canthus of the eye for $4-5 \mathrm{~cm}$ in a posterosuperior direction. The artery is often located near the hairline, and may be visible, particularly in thinner individuals (Fig. 3).

\section{Occipital artery}

The examiner stands in front of the patient and places the forefinger over the occipital tissues horizontally between the ear and the midline, just above the level of the superior nuchal line, exerting forward pressure and compressing $3-4 \mathrm{~cm}$ of tissue against the skull (Fig. 4).

\section{Posterior auricular artery}

The examiner stands behind the patient and exerts upward pressure with the fingertip into the depression between the cartilage of the pinna and the mastoid process (Fig. 5).

\section{Supraorbital, supratrochlear, and angular arteries}

The examiner stands behind the patient, and with the fingertip against the root of the nose compresses the supraorbital soft tissues against the supraorbital rim (Fig. 6).

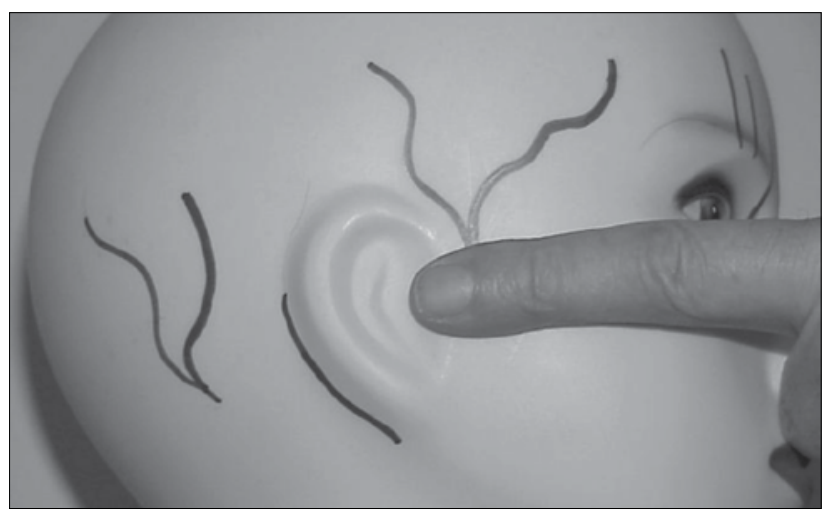

Fig. 2. Compression of the main trunk of the superficial temporal artery.

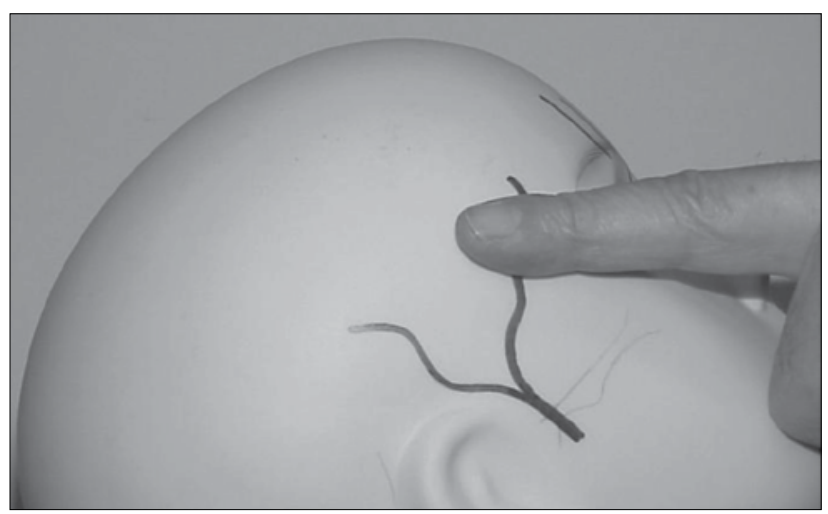

Fig. 3. Compression of the frontal branch of the superficial temporal artery. 


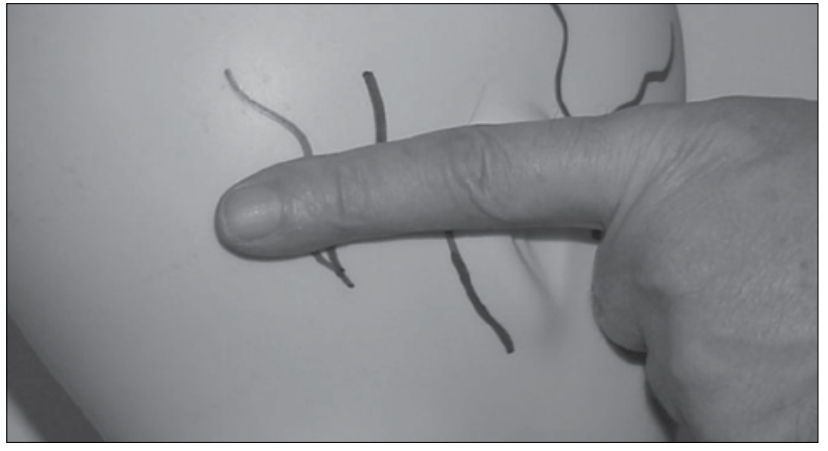

Fig. 4. Compression of the occipital artery.

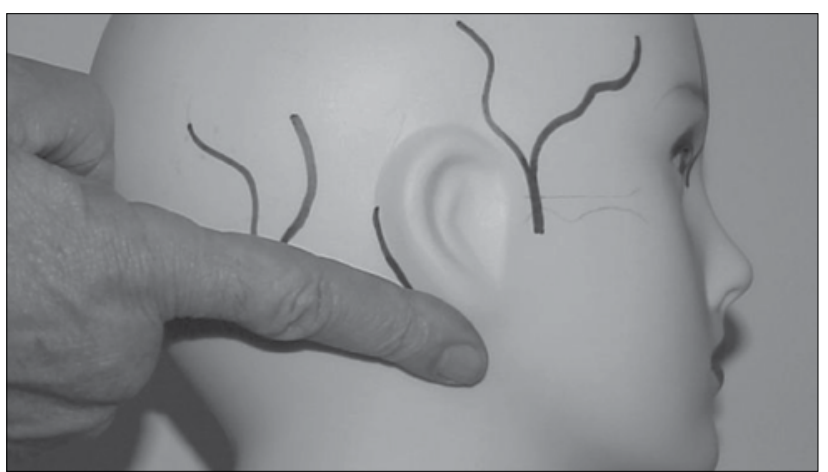

Fig. 5. Compression of the posterior auricular artery.

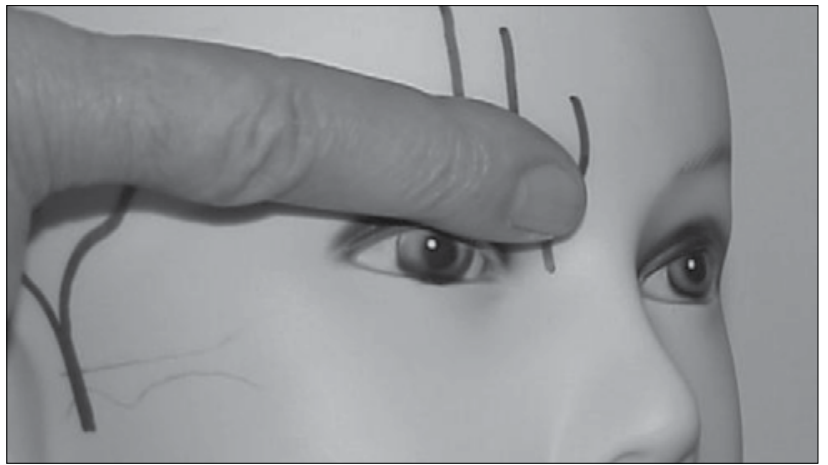

Fig. 6. Compression of the angular, supraorbital, and supratrochlear arteries.

\section{Results}

The longer an attack lasts, and the more severe the attack, the less likely that digital compression will provide an accurate diagnosis. It is well known that the vasoconstrictors, the triptans, are less effective and sometimes have no effect, even in patients with proven arterial pain, if the headache has been allowed to become very severe before the medication is used. The same occurs with digital artery compression.

It is also of interest that arterial compression sometimes relieves pain in an area not supplied by the compressed artery. Commonly, compression of the occipital arteries relieves peri-orbital pain, and compression of the superficial temporal main trunk may on occasion relieve occipital pain. The reason for this may lie in the extensive anastomoses that exist between the terminal branches of the external carotid arteries, both ipsilateral and contralateral. ${ }^{[10]}$

\section{Discussion}

The first recorded reference to the involvement of the extracranial vasculature in headache is attributed to Abu Qasim al-Zahrawi
(AD 936 - 1013), the renowned Moorish physician (known in the West as Abucalsis or Abulcasis). More recently, Hare observed 'headache ... to diminish in intensity locally when the particular artery which supplies the affected area is pressed on. ${ }^{[16]} \mathrm{He}$ found that compressing the occipital, the superficial temporal, or the angular artery relieved the headache over the distribution of the relevant vessel. Since then, reduction in the pain of migraine headache by digital compression of one or more of the superficial extracranial arteries has been extensively documented..$^{[17,20,22,23]}$ In a study of 63 migraineurs, digital compression of the ipsilateral superficial temporal artery during migraine headache temporarily reduced or eliminated the pain in $23(36 \%)$ cases. $^{[3]}$

The diagnosis of the origin of the pain in migraine is essential to ensure the prescription of the appropriate treatment. This highlights the importance of developing a protocol for determining the origin of the pain in each patient. A logical examination sequence has been presented that enables an accurate assessment to be made of which extracranial vessels, if any, are the source of pain in individual migraineurs.

Acknowledgements. None.

Author contributions. Sole author.

Funding. None.

Conflicts of interest. None.

1. Rasmussen BK, Jensen R, Schroll M, Olesen J. Epidemiology of headache in a general population prevalence study. J Clin Epidemiol 1991;44(11):1147-1157. https://doi.org/10.1016/0895-4356(91)90147-2 Shevel E, Spierings EH. Role of the extracranial arteries in migraine headache: A review. Cranio 2004;22(2):132-136. https://doi.org/10.1179/crn.2004.017

Drummond PD, Lance JW. Extracranial vascular changes and the source of pain in migraine headache. Drummond PD, Lance JW. Extracranial vascular changes and the source
Ann Neurol 1983;13(1):32-37. https://doi.org/10.1002/ana.410130108

Ann Neurol 1983;13(1):32-37. https://doi.org/10.1002/ana.410130108
4. Shevel E. Cervical muscles in the pathogenesis of migraine headache. J Headache Pain 2004;5(1):12-14. Shevel E. Cervical muscles in the pathogenesis of
https://doi.org/10.1007\%2Fs $10194-004-0062-0$

https://doi.org/10.1007\%2F $10194-004-0062-0$
5. Tfelt-Hansen P, Lous I, Olesen J. Prevalence and significance of muscle tenderness during common migraine attacks. Headache 1981;21:49-54. https://doi.org/10.1111/j.1526-4610.1981.hed2102049.x

Andersen AR, Tfelt-Hansen P, Lassen NA. The effect of ergotamine and dihydroergotamine on cerebral blood flow in man. Stroke 1987;18(1):120-123. https://doi.org/10.1161/01.str.18.1.120

7. Hachinski V, Norris JW, Edmeads J, Cooper PW. Ergotamine and cerebral blood flow. Stroke 1978;9(6):594-596. https://doi.org/10.1161/01.str.9.6.594

8. Schumacher G, Wolff H. Experimental studies on headache: A. Contrast of histamine headache with the headache of migraine and that associated with hypertension. B. Contrast of vascular mechanism in pre-headache and in headache phenomena of migraine. Arch Neurol Psychiat 1941;45(2):199-214. https://doi.org/10.1001/archneurpsyc.1941.02280140009001

9. Jansen I, Edvinsson L, Mortensen A, Olesen J. Sumatriptan is a potent vasoconstrictor of human dural arteries via a 5-HT1-like receptor. Cephalalgia 1992;12(4):202-205. https://doi.org/10.1046/j.14682982.1992.1204202.x

10. Marty F, Montandon D, Gumener R, Zbrodowski A. Subcutaneous tissue in the scalp: Anatomical, physiological, and clinical study. Ann Plast Surg 1986;16(5):368-376. https://doi.org/10.1097/00000637 198605000-00004

11. Stock AL, Collins HP, Davidson TM. Anatomy of the superficial temporal artery. Head Neck Surg 1980;2(6):466-469. https://doi.org/10.1002/hed.2890020604

12. Imanishi N, Nakajima H, Minabe T, Chang H, Aiso S. Venous drainage architecture of the temporal and parietal regions: Anatomy of the superficial temporal artery and vein. Plast Reconstr Surg 2002;109(7):2197-2203. https://doi.org/10.1097/00006534-200206000-00003

13. Abul-Hassan HS, von Drasek Ascher G, Acland RD. Surgical anatomy and blood supply of the fascial layers of the temporal region. Plast Reconstr Surg 1986;77(1):17-28. https://doi.org/10.1097/00006534-198601000-00004

14. Bergman RA, Afifi AK, Miyauchi R. Illustrated Encyclopaedia of Human Anatomic Variation: Opus II. Cardiovascular System. Arteries: Head, Neck, and Thorax. 2002. http://www.vh.org/adult/provider/anatomy/ AnatomicVariants/Cardiovascular/Text/Arteries/TemporalSuperficial.html (accessed 21 June 2017).

15. Williams PL, Warwick R, Dyson M, Bannister L. Gray's Anatomy. London: Churchill Livingstone, 1989.

16. Hare F. Mechanism of the pain in migraine. Med Pr 1905;1:583.

16. Hare F. Mechanism of the pain in migraine. Med Pr 1905;1:583.
17. Louis S. A bedside test for determining the sub-types of vascular headache. Headache 1981;21 (3):87 . Louis S. A bedside test for determining the sub-types of vasc
88. https://doi.org/10.1111/j.1526-4610.1981.hed2103087.x

18. Vijayan N. Head band for migraine headache relief. Headache 1993;33(1):40-42. https://doi. Vijayan N. Head band for migraine he.
org/10.1111/j.1526-4610.1993.hed $3301040 . x$

19. Graham JR, Wolff HG. Mechanism of migraine headache and action of ergotamine tartrate. Arch Neurol Psychiat 1938;39 (4):737-763. https://doi.org/10.1001/archneurpsyc.1938.02270040093005

20. Pickering GW. Experimental observations on headache. BMJ 1939;1(4087):907-912. https://do org/10.1136/bmj.1.4087.907

21. Tunis MM, Wolff HG. Analysis of cranial artery pulse waves in patients with vascular headache of the migraine type. Am J Med Sci 1952;224:565-568. https://doi.org/10.1097/00000441-195211000-00013

22. Lipton SA. Prevention of classic migraine headache by digital massage of the superficial tempora arteries during visual aura. Ann Neurol 1986;19(5):515-516. https://doi.org/10.1002/ana.410190521 23. Shevel E. The role of the external carotid vasculature in migraine. In: Clarke LB, ed. Migraine Disorders Research Trends. New York: Nova Science Publishers, 2007. 